\title{
Editorial
}

\section{Número temático: “Amor, inspiración y logos en el pensamiento antiguo"}

\author{
María Angélica Fierro \& Ana Carolina Delgado
}

Desde hace ya más de una década la revista Nuevo Itinerario, con el apoyo del Instituto de Filosofía de la Universidad Nacional del Noreste, se ha constituido en un espacio de difusión de los trabajos de los investigadores nacionales, regionales e internacionales que profundizan diferentes tópicos con el objetivo fundamental de mantener la amplitud de miradas sobre temas que ocupan a los expertos, ya sea por sus intereses personales o disciplinares o bien por la demanda de las problemáticas que surgen dentro de nuestro contexto sociocultural y que ameritan su indagación.

El número temático "Amor, inspiración y logos en el pensamiento antiguo" tuvo su surgimiento en el Taller de Filosofía Antigua "Realidad y condición humana en el pensamiento antiguo" realizado en el Instituto de Filosofía - Facultad de Filosofía y Letras, Universidad de Buenos Aires, en julio de 2018. En él se presentaron versiones preliminares de los trabajos del presente volumen, ${ }^{1}$ a las que se agregaron contribuciones de otros investigadores. Su eje es la naturaleza misteriosa de la pasión amorosa así como el tipo de conocimiento que proporciona la inspiración a través de un contacto directo con una dimensión divina de la realidad que aparecen ya como motivos de reflexión en los poemas homéricos y hesiódicos y que son, luego, retomados bajo distintos ropajes en la literatura y filosofía grecorromanas. El reconocimiento del innegable poderío de erōs a nivel humano e, incluso, cósmico condujo a consideraciones tendientes a comprender la conmoción erótica, doblegarla, evitarla, rendirse a su tiranía, o, eventualmente, reorientarla de modo constructivo. Asimismo la comunicación con los dioses, implicada en el estado inspirado de profetas y adivinos, de los poetas y de los iniciados en la religiones mistéricas, fue tematizada y sometida a consideración crítica desde la filosofía por oponerse, en principio, a los modos específicos de una investigación racional dirigida por el logos. El acceso a la realidad mediante el camino dialéctico parecería, efectivamente, producirse a partir de una ruptura drástica con los modos que encuentran su origen en el erōs y el enthousiasmos.

Los trabajos que recogemos, a continuación, han sido organizados en torno a estos tres tópicos - erōs, enthousiasmos y logos -, atendiendo, a su vez, al período de tiempo en que han tenido lugar las diferentes reflexiones sobre ellos; de este modo, creemos, se visualiza con mayor claridad el diálogo intelectual que logra entablarse entre los distintos pensadores.

Un complejo tratamiento del amor en el mito se encuentra desarrollado en "Secretos en la montaña. Las marcas de la proximidad: amor, inspiración y palabra verdadera" de la Prof. Cecilia Colombani quien analiza en el Proemio de la Teogonía, a través del rastreo de marcas lexicales significativas, la relación de transferencia que se establece entre Zeus y sus hijas las Musas, y a la vez cómo ellas, por ser herederas legítimas del Padre, trasladan su voz al poeta. Estos campos se articulan, a su vez, con la función que cumplen el canto, la poesía, la memoria y el olvido en la sociedad griega

\footnotetext{
${ }^{1}$ En tal sentido agradecemos especialmente al Prof. Eduardo Sinnott y al Prof. John Thorp por haber reformulado sus respectivas conferencias para dicho evento a fin de incluirlas como trabajos del presente número temático.
} 
antigua y que dan cuenta de un tiempo histórico en el que se enraíza el poema hesiódico. Muestra así que la relación que se entabla entre las Musas y el poeta como su fiel servidor es a partir de la lógica del don ya que la palabra divina como palabra inspirada supone una elección divina que se materializa en iniciación e inspiración.

La Prof. Lidia Raquel Miranda realiza una "arqueología del amor", esto es, rastrea las distintas representaciones con que la literatura grecorromana ha representado este fenómeno en las figuras de Afrodita y Eros. Efectivamente, "Arqueología del amor: la representación de Afrodita y de Eros en el pensamiento antiguo" constituye un trabajo minucioso, sin pretensiones de exhaustividad, de los textos literarios en los que aparecen episodios míticos cuyos protagonistas son tales deidades. El panorama resultante del estudio permite recomponer una cierta teorización filosófica presente en el mundo antiguo acerca del tema del amor.

En "Atenas, entre el amor y la anarquía: la democratización de los placeres y las contingencias de la política popular", el Prof. Julián Gallego analiza la peculiar transposición de la lógica de las relaciones eróticas a la lógica de la política que tiene lugar en el contexto cultural griego. En este sentido, reconstruye la crítica a la democracia que se puede detectar en pasajes de las obras de distintos pensadores (Tucídides, Aristófanes, Platón, Aristóteles, Isócrates). La finalidad argumentativa que persiguen estos autores, se aduce, es similar, a saber, buscan justificar la sustracción al pueblo de la posibilidad de realizar sus deseos y disfrutar de los placeres y la restricción del ejercicio del poder político por parte de una élite especialmente cualificada. En este análisis se entrecruzan, de manera muy interesante, la perspectiva historiográfica con la filosofía y el análisis político.

Una aproximación novedosa al Banquete platónico nos ofrece el trabajo de la Prof. Fernanda Pio y el Prof. Gabriele Cornelli "O que esta mulher está fazendo aqui? A coragem de Alceste no Banquete de Platão" en el que los autores se enfocan en la insólita mención de una mujer, Alcestis, en el discurso laudatorio a Erōs de Fedro. En tal sentido analizan la significación de que Alcestis aparezca en el contexto pederástico de este discurso nada menos que como un ejemplo de andreia -una virtud típicamente masculina- en razón de ser capaz, a la manera de los soldados de un ejército formado por amantes y amados, de un acto de amor supremo, a saber, morir por su esposo Admeto a fin de librarlo de una temprana muerte. Muestran asimismo que esta reivindicación del coraje de Alcestis se basa en su comparación con dos figuras masculinas. Por una parte, su valentía opaca al ánimo frágil y temeroso de Orfeo en su empresa fallida en el Hades para rescatar a su amada Eurídice; por otra parte, se equipara a la andreia del mayor héroe griego, Aquiles, si bien este muere, a diferencia de Alcestis, por su amigo ya fallecido, Patroclo, y sin hallarse poseído por los dioses por ser el amado, no el amante. De este recorrido, los autores concluyen que el fin de esta atípica aparición del personaje femenino de Alcestis es el de destacar la excepcionalidad del poderío de Erōs a través de presentar su conducta heroica como ejemplo de la andreia, virtud de la que habitualmente solo los hombres son fieles representantes.

Por su parte, en "El erōs de Alcibíades. Entre Sócrates y la philotimia" la Prof. Carolina Modenutti ofrece, por su parte, una mirada política sobre uno de los grandes textos platónicos acerca de erōs - el Banquete- al abordarlo desde la perspectiva que ofrece el relato vivencial de Alcibíades. Muestra así que, en tanto este personaje responde a la configuración psíquica de un timócrata, amante de la fama y los honores, y por tanto es la búsqueda de la timē lo que guía sus acciones, su philotimia complemen- 
ta la concepción de erōs que presenta el discurso de Sócrates, ya que aporta el componente político, aparentemente dejado de lado en la presentación metafísico/religiosa de este. De tal modo, Alcibíades, a partir de su condición natural de político y amante de los honores, no resulta ser necesariamente un mal amante o un amante a medio camino, sino más bien un poseedor de un tipo de deseo que puede articularse apropiadamente con el del amante de la sabiduría, en este caso con el de Sócrates.

En cuanto a la Prof. María Angélica Fierro nos propone visitar el tema de erōs, esta vez en relación con la mania, en el otro gran texto platónico sobre el amor, el $\mathrm{Fe}$ dro. En tal sentido muestra que allí Platón retoma del contexto cultural los rasgos compartidos y diferenciales entre locura ordinaria y locura divina a fin de legitimar la locura erótica divina como la mejor de entre las de tal procedencia y convertirla en una vía privilegiada de comprensión del sentido último de la realidad y de mejoramiento personal. En esta línea, señala cómo en la presentación platónica la locura amorosa ordinaria y la divina coinciden en remitir al mismo estado psicofísico en el amante -el apetito sexual exacerbado del amante al descubrir los atractivos del hermoso joven-; también, en conmocionarlo al punto de generar similares conductas extravagantes e insensatas para los más. El erōs físico, junto con el resto de los apetitos, resulta ser entonces un aspecto inextirpable de nuestra alma, que estimula y potencia el deseo metafísico de la razón, si bien precisamente a través de su renuncia a la concreción de sus apetencias. De este modo, la razón se convierte en la expresión más elevada y poderosa de la locura erótica por la belleza, al promover una captación directa, aunque sesgada, del entramado eidético y motivar y complementar la investigación reflexiva a través de la dialéctica. Finalmente, la autora aborda la vinculación entre la locura amorosa y la estimulación de tres formas de la anamnēsis: el recuerdo de la visión directa de la Belleza pura; la reconstrucción dialéctica del entramado de lo real; el descubrimiento del patrón de configuración psíquica divina al que corresponde el alma del amante-filósofo y su amado.

En las teorizaciones acerca del amor, un lugar obligado es, naturalmente, la recepción posterior de las reflexiones platónicas al respecto. Se ha interpretado que, según el filósofo ateniense, la importancia del amor residiría en el potencial que este puede ejercer sobre el alma remitiéndola hacia la idea de Belleza. La postura platónica insistiría en el interés dialéctico del amor, pero comportaría, al mismo tiempo, un inevitable olvido del individuo y del amor individual en sí, en la medida en que este se constituiría en mero recurso para llegar a otra instancia, instancia que sería la verdaderamente relevante. En "El individuo como objeto de amor en Plutarco" el Prof. Ezequiel Ludueña analiza el tema del amor del individuo y, por transitividad, la interpretación mencionada, tal como viene presentado por Plutarco en el diálogo Erótico. Allí el filósofo asume una serie de tópicos claramente procedentes de la filosofía platónica y hace de ellos una apropiación que difiere de la interpretación anterior. Como sintetiza Ludueña, "el punto culminante del camino a la Belleza es la relación con una persona en particular, y esa relación supone no una experiencia puntual, una suerte de experiencia mística, sino una continua búsqueda en una relación estable con otro ser humano".

Un renovador abordaje sobre estas temáticas presenta el trabajo de la Prof. Milena Luz Lozano Nembrot "Los pliegues de la subjetividad: individuo y responsabilidad moral en la Grecia Antigua" en el cual trata la problemática de los cambios y continuidades a este respecto dentro de la moral griega. Para ello releva las principales co- 
rrientes exegéticas respecto de este tema, distinguiendo entre dos líneas principales de interpretación -la evolucionista y la continuista- para luego proponer como un posible punto de partida, el desarrollo del concepto de la enkrateia o dominio de sí. Muestra entonces cómo el interés por este modo de comportamiento, su expresión en el lenguaje y su conceptualización comienzan en el siglo $\mathrm{V}$ a.C. y continúan su desarrollo en el IV, cuando aparece por primera vez la palabra enkrateia. De ello concluye de qué modo, sin apelar a una teleología, se registra en esta noción una clara transformación en la moral griega, que coloca en el centro de la escena el problema del dominio de los placeres, considerados como una parte del yo que hay que controlar y que constituye así un primer "pliegue" en la subjetividad. En tal sentido rescata la teoría foucaultiana en relación con estos temas dado que, desde un punto de vista genealógico nietzscheano, en vez de centrarse en los detalles de cada filósofo o cada género, intenta ofrecer una mirada general de la moral antigua clásica y la utiliza para pensar su propia filosofía y los desafíos para la reflexión ética actual. A partir de ello la autora sugiere que los griegos y su forma de pensar al ser humano pueden servir como un otro a partir del cual desnaturalizar ciertas formas de la cultura vigente, jugar a abstraernos de las circunstancias particulares y registrar los puntos de encuentro que podemos tener en nuestro diálogo con los antiguos.

Adoptando la teorización platónica, si bien de manera creativa, Proclo establece una diferenciación - según él, realizada ya por el ateniense - entre una poesía inspirada, otra que sería epistémica y, finalmente, la mimética. A ellas correspondería un tipo distinto de vida del alma, y de ellas dependería también la factibilidad de efectuar o no la necesaria conversión del alma. En "Proclo: el papel soteriológico de la poesía inspirada", el Prof. José María Nieva muestra el modo en que Proclo entiende que ha de darse la unificación del alma para que pueda obtener la experiencia extática con lo Uno y analiza el papel específico que la poesía desempeña en el logro de esa unificación. La poesía cumple, concluye el autor, un peculiar poder salvador para el hombre.

También el lón platónico trata sobre la poesía. Y particularmente conocido es el tópico de la inspiración divina como fenómeno del que brotaría nada menos que la creación poética. La Prof. Ana Carolina Delgado en "Inspiración poética y conocimiento en el lon platónico" se concentra en el que es, según su interpretación, el tema principal de la obra, i.e. la hermenéutica como práctica discursiva. El motivo de la inspiración divina tal como es presentado en el discurso central del diálogo constituye, no el tópico principal del lón platónico, sino la contracara del examen filosófico relacionado con las técnicas discursivas. Estas, si van desvinculadas del conocimiento del correlato externo del discurso con el que tratan, se constituyen en una mera práctica y nunca en técnica. Y de técnica es precisamente de lo que carece el inspirado; de manera que la inspiración es carencia de conocimiento, pero, según entiende la autora, a diferencia de otras interpretaciones, esto no implica que la inspiración divina sea un modo superior de acceso a la realidad.

En cuanto al trabajo del Prof. John Thorp "La cama de Platón. Esencia y arquetipo en la teoría de las Formas" aborda uno de los problemas capitales de la metafísica platónica, a saber la tensión profunda y fundamental presente en la Teoría de las Formas entre comprenderlas como arquetipos y/o como esencias. En tal sentido, muestra, con especial referencia a la idea de cama que aparece en el libro X de la República, que, mientras un arquetipo constituye un ejemplo preeminente de su clase que incorpora los estándares más altos en sus virtudes particulares, una esencia, en cambio, refiere al denominador común más alto de una clase de cosas, sus condiciones necesa- 
rias y suficientes si se quiere. El nudo conflictivo es que Platón parece inclinarse más por una u otra concepción en diferentes momentos de su obra, pero sin advertir claramente la diferencia entre ambas. De este modo del vientre de su pensamiento metafísico se habrán de desprender dos grandes corrientes divergentes en filosofía: la que consolida Aristóteles y sus continuadores, quienes tomaron la idea de que los universales eran esencias porosas, repletas de potencialidades más que de actualidades; la de los neo-platonistas, que entendieron a los universales como arquetipos ricos que emanan ser a las entidades inferiores que caen bajo ellos.

En "Notas acerca de la significación en Platón y en Aristóteles", el Prof. Eduardo Sinnott ofrece un detallado análisis de la visión aristotélica sobre la significación lingüística y defiende que, a diferencia de lo que habitualmente suele sostenerse, el esquema propuesto por el Estagirita comprende ya la distinción entre significado y referencia; diferenciación que, como se sabe y con todas las matizaciones del caso, caracteriza las modernas formas de explicar todo proceso de significación. Para defender esta tesis novedosa, el trabajo explora lugares del corpus aristotélico que, obviados en otros estudios, permiten advertir la presencia de esta diferenciación en el planteamiento del filósofo, reconstruir de manera completa su postura y apreciar el verdadero alcance explicativo que la misma comporta.

El lector encontrará en este volumen, como se puede ver, un espectro amplio de tratamientos relativos a las temáticas amor, inspiración y logos. En ellos hallará también una interesante diversidad de planteamientos; diversidad que resulta siempre estimulante para el pensamiento y para el replanteamiento de ideas asumidas acerca de las temáticas tratadas o de interpretaciones instaladas acerca de las mismas. En este sentido, queremos manifestar nuestro agradecimiento a los autores que han participado con sus contribuciones en la composición del presente volumen monográfico. El proyecto emprendido ha llegado a puerto también, y de manera muy competente, gracias al trabajo conjunto con Flavio Guglielmi de la revista Nuevo Itinerario, quien estuvo continuamente disponible para llevar a cabo diligentemente la tarea editorial. Vaya para él también nuestro agradecido reconocimiento. 